\title{
Utilization of citrus plant waste (peel) for the development of food product
}

\author{
Muhammad Iftikhar ${ }^{1}$, Said Wahab ${ }^{1}$, Naveed ul Haq ${ }^{2}$, Saima Naz Malik ${ }^{3}$, \\ Safa Amber ${ }^{4}$, Najeeb Ullah Taran ${ }^{1}$ and Shams Ur Rehman² ${ }^{2 *}$ \\ 1. Department of Food Science and Technology, The University of Agriculture Peshawar-Pakistan \\ 2. Department of Food Science and Technology, The University of Haripur-Pakistan \\ 3. Hazara Agriculture Research Station Abbottabad, Khyber Pakhtunkhwa -Pakistan \\ 4. Institute of Food and Nutritional Sciences, PMAS-Arid Agriculture University Rawalpindi-Pakistan \\ *Corresponding author's email: srawan1@yahoo.com
}

Citation

Muhammad Iftikhar, Said Wahab, Naveed ul Haq, Saima Naz Malik, Safa Amber, Najeeb Ullah Taran and Shams Ur Rehman. Utilization of citrus plant waste (peel) for the development of food product. Pure and Applied Biology. Vol. 8, Issue 3, pp1991-1998. http://dx.doi.org/10.19045/bspab.2019.80143

\begin{tabular}{llll}
\hline \hline Received: 27/02/2019 & Revised: 29/07/2019 & Accepted: 03/08/2019 & Online First: 06/08/2019 \\
\hline
\end{tabular}

\section{Abstract}

Citrus peels, the waste by-products of citrus juices factories are valuable healthful functional food (fiber, mineral and antioxidants). The present investigation performed to assess the nutritional status of fortified cake with citrus sinensis (sweet orange) peels powders. Citrus peel and fine flour contains moisture $7.62 \%, 9.82 \%$, protein $4.53 \%, 10.55 \%$, fat $3.82 \%, 1.52 \%$, fiber $63.45 \%, 1.77 \%$ and ash $4.63 \%, 4.14 \%$. Different level of orange peel from $1 \%-5 \%$ were blended with wheat flour to produce composite flour. Ash content increased from 1.00 to 2.00\%, Moisture showed reduction from $24.32 \%$ (T0) to $15.96 \%$ (T5), Crude protein was reduced from $12.00 \%$ (T0) to $11.02 \%$ (T5), crude fat content increased from $13.05 \%$ (T0) to $15.34 \%$ (T5), and crude fiber increased from $2.00 \%$ (T0) to $6.46 \%$ (T5). Citrus peel cakes were found reasonably different just as subjected to organoleptic analysis. Mean values for color T0 (7.20)-T5 (6.33), taste, T0 (7.13)-T5 (6.14), texture T0 (7.23)-T5 (6.54), overall acceptability T0 (7.19)-T5 (6.34). From the current results it is concluded that blending of wheat flour up to $3 \%$ citrus peel flour is suitable for cake development with acceptable sensory attributes and the addition of peel powder in cake increases its nutritional and functional attributes.

Keywords: Citrus peel; Citrus peel fortified cake; Organoleptic attributes; Proximate constituents; Wheat flour

\section{Introduction}

Citrus is the most abundant in the earth; with orange, grapefruit, lemon are the most regular citrus fruits [1]. World's production of citrus is 115.52 million tons, and in Pakistan it is resided at the area of 199,000 hectares with total production of 2007.0 thousand tones in Pakistan [2]. Citrus is consist of two separate regions the endocarp and the pericarp, the pericarp is consist of peel that contain large number of aromatic oil glands, which gives a particular smell and gloss [3]. The mass of peel is $50-60 \%$ to the total mass of citrus fruit that is disposed of as waste martial after processing, which can be converted in to value added products or fortified with food products to increase the nutritional profile [1]. If this waste is not utilized this can cause fabricate bad smell, 
soil contamination, harborage for insects and causes severe pollution of environment [3]. A large part of this production is use for juice extraction of citrus in the industries leaving at the back massive amounts of remaining waste containing peel and segment membranes. Peels cover of about 50 to $60 \%$ of total weight of fruits and left as the most important by product [4].

The phytochemicals including vitamins, cumarins, terpenoids, flavonoids, carotenoids, lignin are present in plant material and plant material have high antioxidant activity due to the existence of these phytochemicals [5]. As citrus peel comprises the phenolic and phlavonoids composite, it hold high anti-oxidant activity. Bioactive composition including anti-oxidants such as ascorbic acid, phenolic compounds, flavonoids and pectins are found in citrus fruits and juices that are essential to human nutrition [6].

Cakes have high importance in bakery due to its taste, texture, flavors and variety of brands present in the market. Recently cereal industry has global market increment with about $1.5 \%$ a year. Cake market having challenges of cost, shelf life and quality attributes [7]. Mostly cake is taken preference from bread and other cereal products due its soft texture and good mouth feel characters. Mostly peoples consume cake because it is a quick source of energy [8].

The major by products from citrus processing is its peel. Citrus peel represents $50-60 \%$ of the total weight of the fruit. The citrus juice industry uses only the pulp portion of the citrus and a considerable amount of peel is discarded as industrial waste. The large amount of waste produced by the food industries causes serious environmental problems and also results in economic losses if not utilized effectively, because it is a substrate for the growth of different pathogen. Although , peel has high nutraceutical value so that it can be used as functional ingredient in form of citrus peel powder for the benefits of pharmaceutical, food and cosmetic industries for health promoting effect which is of vital importance, this way we can utilize the peel waste and protect our environment from pollution created due to waste of citrus peel. Because the citrus especially its peel portion is a source of significant anti-oxidants so its inclusion in the cakes was attempts to develop a cake with improved antioxidant activity along with additional nutrients which was the plan of the current study. Consequently, the plan of this study was to estimate the sensory profile and preference mapping of cakes supplemented with citrus peel.

\section{Materials and methods Materials}

The materials used in the investigation were wheat flour, sodium chloride, soybean oil, fresh eggs, baking powder, Sugar were purchased from the local market of Peshawar City. Citrus peel were collected from District Battagram; KPK, and transported to FST (food science and technology) Lab of Agriculture University Peshawar.

\section{Processing of cake}

The cake formula in this study was adapted from the work of [9]. The formula of cakes at six different citrus peel powder levels is shown below in table 1 .

\section{Preparation of citrus peel powder}

Citrus peel were removed from citrus, then the peel were boiled in water (1:4 peels: water) for about 10 minutes and then put in an oven at a temperature of $70^{\circ} \mathrm{C}$ for 24 hours. After drying the peels were ground to flour to a particle size of less than $0.2 \mathrm{~mm}$, then citrus peel powder were packed in poly ethylene bags and stored for further use [10].

\section{Preparation of cake}

Citrus peel powder were infused with boiling water for $5 \mathrm{~min}$ in a bowl and cooled to 24$26^{\circ} \mathrm{C}$. Whole egg and egg yolk were poured into a bowl, and mixed by hand with an 
eggbeater. Sweetener and sodium chloride were added to the bowl, and then warmed to $40^{\circ} \mathrm{C}$ over a hot water bath. Ingredients were mixed by hand with a plastic scraper until smooth. The cake butter was immediately deposited into cake pans. For each cake, $250 \mathrm{~g}$ of mixture were poured into a cake pan (20.3 $\mathrm{cm}$ in diameter $7 \mathrm{~cm}$ in height) and baked at $160^{\circ} \mathrm{C}$ for $40 \mathrm{~min}$ in a preheated oven (30mins) (Table 2). The cakes were allowed to cool for 2 hours, and then were removed from the pans. The cooled cakes were packed in polypropylene bags at room temperature before physicochemical and organoleptic analyses [11].

Table 1. Treatment Combinations

\begin{tabular}{|c|c|c|c|}
\hline S. No & Treatments & Cake flour \% & Citrus Peel Powder \% \\
\hline $\mathbf{1}$ & T0 & $100 \%$ & $0 \%$ \\
\hline $\mathbf{2}$ & T1 & $99 \%$ & $1 \%$ \\
\hline $\mathbf{3}$ & T2 & $98 \%$ & $2 \%$ \\
\hline $\mathbf{4}$ & T3 & $97 \%$ & $3 \%$ \\
\hline $\mathbf{5}$ & T4 & $96 \%$ & $4 \%$ \\
\hline $\mathbf{6}$ & T5 & $95 \%$ & $5 \%$ \\
\hline
\end{tabular}

Control T0 (100\% wheat flour, 0\% peel powder), T1 (99\% wheat flour, $1 \%$ peel powder), T2 (98\% wheat flour, $2 \%$ peel powder), T3 (97\% wheat flour, 3\% peel powder), T4 (96\% wheat flour, $4 \%$ peel powder), T5 (95\% wheat flour, $5 \%$ peel powder)

Table 2. Formulation of cakes

\begin{tabular}{|c|c|c|c|c|c|c|c|}
\hline S. No & Ingredient (g) & Control & T1 & T2 & T3 & T4 & T5 \\
\hline $\mathbf{1}$ & Cake flour & 190 & 187.5 & 185 & 182.5 & 180 & 177.5 \\
\hline $\mathbf{2}$ & OP Powder & 0 & 2.5 & 5 & 7.5 & 10 & 12.5 \\
\hline $\mathbf{3}$ & Sugar & 258 & 258 & 258 & 258 & 258 & 258 \\
\hline $\mathbf{4}$ & Whole egg & 258 & 258 & 258 & 258 & 258 & 258 \\
\hline $\mathbf{5}$ & Egg yolk & 57 & 57 & 57 & 57 & 57 & 57 \\
\hline $\mathbf{6}$ & Salt & 3 & 3 & 3 & 3 & 3 & 3 \\
\hline $\mathbf{7}$ & Soybean oil (ml) & 38 & 38 & 38 & 38 & 38 & 38 \\
\hline $\mathbf{8}$ & Water (ml) & 84 & 84 & 84 & 84 & 84 & 84 \\
\hline
\end{tabular}

Control T0 (100\% wheat flour, $0 \%$ peel powder), T1 (99\% wheat flour, $1 \%$ peel powder), T2 (98\% wheat flour, $2 \%$ peel powder), T3 (97\% wheat flour, 3\% peel powder), T4 (96\% wheat flour, $4 \%$ peel powder), T5 (95\% wheat flour, $5 \%$ peel powder)

\section{Chemical analysis}

Moisture contents were determined at (Model: 605, Precision Oven, Thermo Fisher Scientific) $105^{\circ} \mathrm{C}$ till constant weight, ash contents were determined by drying the sample and then placed in muffle furnance (muffle furnace, lef-2055-0, Daihan Labtech, Korea) at $550^{\circ} \mathrm{C}$, crude fat contents were estimated by using soxhlet apparatus us diethyl ether as solvent, crude fiber contents were determined by digesting the moisture and fat free samples with both acid $(1.25 \%$ sulphuric acid) and alkali solution (1.25\% sodium hydroxide solution), crude protein contents were estimated by using Kjeltech apparatus, sulphuric acid and digestion mixture of copper sulphate, iron sulphate and potassium sulphate for digestion process and after distillation the sample is titrated against $0.25 \mathrm{~N}$ sulphuric acid (Kjel Tech apparatus) were measured [12].

Organoleptic analysis

Samples of the cake were evaluated for color, taste, flavor and overall acceptability by a 
panel of ten judges. The evaluation was carried out by using 9 points hedonic scale [12].

\section{Statistical analysis}

Data were analyzed by using one way analysis of ANOVA (analysis of variance) and means were compared by applying LSD (Latin square design) at alpha 0.05 [13].

\section{Results and discussion}

\section{Chemical analysis of wheat flour and citrus peel flour}

Raw ingredients including wheat flour and citrus peels flour were analyzed for proximate composition (moisture, crude protein, crude fat, crude fiber and ash content) and data obtained is shown in table 3. The result for proximate composition of citrus peel flour was carried out and shows moisture $(7.62 \%)$, crude protein $(4.53 \%)$, crude fat $(3.82 \%)$, crude fiber $(63.45 \%)$ and ash $(4.63 \%)$. The data obtained were shown very close association with [14], [15], [16]. Proximate composition of wheat flour was obtained as moisture content $(9.82 \%)$, crude protein $(10.55 \%)$, crude fat $(1.52 \%)$, crude fiber $(1.77 \%)$ and ash content $(4.14 \%)$. The results were in agreement with the investigation of [17], [18]. Citrus sinensis peel is a good source of fiber and fat as compare to wheat flour, if we incorporate citrus peel with wheat flour as an additional ingredient for cake preparation it can produce dynamic effect on cake by increasing the nutritional value, functional properties and overall acceptance of the product.

Table 3. Proximate contents of citrus peel powder and wheat flour

\begin{tabular}{|c|c|c|c|c|c|}
\hline Sample type & Moisture \% & Protein \% & Fat \% & Fiber \% & Ash \% \\
\hline Citrus peel & $7.62 \% \pm 0.12$ & $4.53 \% \pm 0.11$ & $3.82 \% \pm 0.09$ & $63.4 \% \pm 1.62$ & $4.63 \% \pm 0.08$ \\
\hline Wheat flour & $9.82 \% \pm 0.15$ & $10.5 \% \pm 0.18$ & $1.52 \% \pm 0.03$ & $1.77 \% \pm 0.03$ & $4.14 \% \pm 0.09$ \\
\hline
\end{tabular}

Mean of three replications with standard error

\section{Proximate analysis of cake fortified with citrus peel}

Analysis of variance showed that the treatments have momentous effect $(\mathrm{p}<0.05)$ on ash, moisture, protein, fat and fiber contents of cake citrus peel (Table 4). Treatments showed increasing trend on ash percentage of cake. Means values of Ash content of citrus peel cake for T0 were (1.00\%), T1 (1.25\%), T2 (1.31\%), T3 $(1.40 \%)$, T4 (1.59\%) and T5 (2.00\%). The maximum mean value of ash $(2.00 \%)$ was noted in $\mathrm{T} 5$ while the minimum mean value $(1.00 \%)$ was noted in T0. The addition of citrus peel up to $4 \%$ has not effect too much on ash content while $5 \%$ peel addition increased the level of ash content more than the other samples T0, T1, T2, T3 and T4. These findings were in agreement with the work of $[6,19]$. The citrus sinensis peels addition up to $5 \%$ showed significant different from other levels of citrus peels.
Moisture content of citrus peel cake decreased with increasing the addition of citrus peel, means values for moisture content of citrus peel cake were T0 (24.32\%), T1(19.80\%), T2 (18.11\%), T3 (17.45\%), T4 $(16.76 \%)$ and T5 (15.96\%). The highest mean value $(24.32 \%)$ was recorded in T0 and the minimum mean value $(15.96 \%)$ was recorded in $\mathrm{T} 5$. The moisture content of the cake were seen to be decreased as the level of citrus peel increased. These results were closely related with the work of $[19,20]$. The moisture content of the citrus peel was found to be less than the wheat that may be the reason of decreasing level of moisture in the cake.

Analysis of variance showed that treatment has pronounced effect on the protein content of citrus peel cake. The mean values for protein content of citrus peel cake were T0 (12.00\%), T1 (11.50\%), T2 (11.38\%), T3 (11.34\%), T4 (11.16\%) and T5 (11.02\%). 
The highest mean value $(12.00 \%)$ was recorded in $\mathrm{T} 0$ while the minimum mean value $(11.02 \%)$ was recorded in T5. All the other treatments were significantly different $(\mathrm{p}<0.05)$ from the control. The reason of decreasing the level of protein content could be the level of protein content was low in citrus peel flour than wheat flour. Similar pattern was also shown by [19-22].

Table 4. Effect of citrus peels flour on proximate composition of cake

\begin{tabular}{|c|c|c|c|c|c|}
\hline Treatments & Ash \% & Moisture \% & Protein \% & Fat \% & Fiber \% \\
\hline \multirow{2}{*}{ T0 } & $1.00 \mathrm{e}$ & $24.32 \mathrm{a}$ & $12.00 \mathrm{a}$ & $13.05 \mathrm{~d}$ & $2.00 \mathrm{f}$ \\
& \pm 0.02 & \pm 0.83 & \pm 0.61 & \pm 0.71 & \pm 0.02 \\
\hline \multirow{2}{*}{ T1 } & $1.25 \mathrm{~d}$ & $19.80 \mathrm{~b}$ & $11.50 \mathrm{~b}$ & $13.50 \mathrm{~cd}$ & $2.89 \mathrm{e}$ \\
& \pm 0.02 & \pm 0.52 & \pm 0.72 & \pm 0.60 & \pm 0.01 \\
\hline \multirow{2}{*}{ T2 } & $1.31 \mathrm{~d}$ & $18.11 \mathrm{c}$ & $11.38 \mathrm{c}$ & $13.96 \mathrm{bcd}$ & $3.78 \mathrm{~d}$ \\
& \pm 0.02 & \pm 0.51 & \pm 0.84 & \pm 052 & \pm 0.04 \\
\hline \multirow{2}{*}{ T3 } & $1.40 \mathrm{c}$ & $17.45 \mathrm{~d}$ & $11.34 \mathrm{c}$ & $14.42 \mathrm{bc}$ & $4.60 \mathrm{c}$ \\
& \pm 0.03 & \pm 0.60 & \pm 0.79 & \pm 0.56 & \pm 0.03 \\
\hline \multirow{2}{*}{ T4 } & $1.59 \mathrm{~b}$ & $16.76 \mathrm{e}$ & $11.16 \mathrm{~d}$ & $14.80 \mathrm{ab}$ & $5.55 \mathrm{~b}$ \\
& \pm 0.03 & \pm 0.75 & \pm 0.67 & \pm 0.51 & \pm 0.04 \\
\hline \multirow{2}{*}{ T5 } & $2.00 \mathrm{a}$ & $15.96 \mathrm{f}$ & $11.02 \mathrm{e} \pm$ & $15.34 \mathrm{a}$ & $6.46 \mathrm{a}$ \\
& \pm 0.02 & \pm 0.68 & 0.73 & \pm 0.62 & \pm 0.05 \\
\hline
\end{tabular}

Mean of three replication with standard error.

T0 (100\% wheat flour, $0 \%$ peel powder), T1 (99\% wheat flour, $1 \%$ peel powder), T2 (98\% wheat flour, $2 \%$ peel powder), T3 (97\% wheat flour, 3\% peel powder), T4 (96\% wheat flour, $4 \%$ peel powder), T5 (95\% wheat flour, $5 \%$ peel powder)

Treatments showed moderately increasing trend on fat percentage of cake. The means fat content of citrus peel cake were T0 $(13.05 \%), \mathrm{T} 1(13.50 \%), \mathrm{T} 2(13.96 \%), \mathrm{T} 3$ $(14.42 \%), \mathrm{T} 4(14.80 \%)$ and $\mathrm{T} 5(15.34 \%)$. The minimum mean value $(13.05 \%)$ was recorded in control that increase up to $(15.34 \%)$ in $\mathrm{T} 5$. The addition of citrus peel up to $4 \%$ has not effect too much on crude fat content while $5 \%$ peel addition increased the level of crude fat content more than the other samples. T5 showed significantly different $(\mathrm{p}<0.05)$ from all other treatments as compared with the control. This increasing pattern was also found in the work of [20-22]. The fat content observed to be more in citrus peel flour than wheat flour, which could be the reason of increment found in crude fat content.

Mean values for crude fiber content of citrus peel cake were T0 (2.00\%), T1 (2.89\%), T2 $(3.78 \%), \mathrm{T} 3(4.60 \%), \mathrm{T} 4(5.55 \%)$ and $\mathrm{T} 5$
(6.46\%). The highest mean value $(6.46 \%)$ was recorded in T5 while minimum mean value was noted in T0 $(2.00 \%)$. The reason of increasing trend observed in the crude fiber content of the cake could be the fiber content was observed to be more in citrus peel flour than wheat flour. The similar pattern was observed and indicates a similar increasing trend in fiber level of cake in the work of [2022].

\section{Organoleptic analysis}

The citrus peel cake analyzed for color, taste, texture and overall acceptability. The sensory analysis was carried out through Larmond scale (hedonic 9-points) by 10 judge's panel. These evaluations are as under [12].

The statistical results revealed that treatments had a notable effect $(\mathrm{p}<0.05)$ on color, taste, texture and overall acceptability of citrus peel cake (Table 5). The Mean score of color for different treatments were T0 (7.20), T1 (7.12), T2 (7.08), T3 (7.18), T4 (6.83) and T5 
(6.33). T0 (7.20) showed maximum increment while the minimum mean occur in T5 (6.33). The results showed that up to $3 \%$ level of citrus peel addition has non significantly different from the control observed by the panelist. While the addition of 4 and $5 \%$ secured less score from the penelists. This may be due to the presence of poly phenols in the citrus peel which give the darker color to the cake [21]. The cake samples were sensory evaluated the judges of the sensory panelists on hedonic scale. The results were closely related to the work of [19], [22]. So the citrus peel up to $3 \%$ addition in cake declared as acceptable by the sensory panelists.

Mean score of taste for different treatments were T0 (7.13), T1 (6.75), T2 (6.82), T3
(6.82), T4 (6.31) and T5 (6.14). Maximum mean score for taste (7.13) was shown in T0 while minimum mean score was shown in T5 (6.14). The addition of citrus peel with 1,2 , 3, 4 and 5\% level in cake has non-significant $(p<0.05)$ effect on taste of cake. the addition of the peel gives bitter taste to the product as reported by [19] All the samples having citrus peels were neither like nor dislike in the taste quality which means citrus peel addition lies in acceptable range on hedonic scale. So it can be concluded that the addition of citrus peels up to $3 \%$ in cake was found to be acceptable like control sample because it is near in score to control sample. The results were closely related to the work of $[19,21]$.

Table 5. Organoleptic analysis of cake fortified with citrus peel

\begin{tabular}{|c|c|c|c|c|}
\hline Treatments & Color & Taste & Texture & Overall Acceptability \\
\hline T0 & $7.20 \mathrm{a} \pm 0.04$ & $7.13 \mathrm{a} \pm 0.05$ & $7.23 \mathrm{a} \pm 0.04$ & $7.19 \mathrm{a} \pm 0.04$ \\
\hline T1 & $7.12 \mathrm{a} \pm 0.05$ & $6.75 \mathrm{~b} \pm 0.04$ & $6.99 \mathrm{~b} \pm 0.03$ & $6.95 \mathrm{c} \pm 0.03$ \\
\hline T2 & $7.08 \mathrm{a} \pm 0.03$ & $6.82 \mathrm{~b} \pm 0.03$ & $7.05 \mathrm{ab} \pm 0.04$ & $7.98 \mathrm{bc} \pm 0.05$ \\
\hline T3 & $7.18 \mathrm{a} \pm 0.03$ & $6.82 \mathrm{~b} \pm 0.04$ & $7.14 \mathrm{ab} \pm 0.03$ & $7.05 \mathrm{~b} \pm 0.05$ \\
\hline T4 & $6.83 \mathrm{~b} \pm 0.04$ & $6.31 \mathrm{c} \pm 0.03$ & $6.77 \mathrm{c} \pm 0.04$ & $6.64 \mathrm{~d} \pm 0.04$ \\
\hline T5 & $6.33 \mathrm{c} \pm 0.05$ & $6.14 \mathrm{~d} \pm 0.05$ & $6.54 \mathrm{~d} \pm 0.05$ & $6.34 \mathrm{e} \pm 0.03$ \\
\hline
\end{tabular}

Mean of three replication with standard error.

0 (100\% wheat flour, $0 \%$ peel powder), T1 (99\% wheat flour, $1 \%$ peel powder), T2 (98\% wheat flour, $2 \%$ peel powder), T3 (97\% wheat flour, 3\% peel powder), T4 (96\% wheat flour, $4 \%$ peel powder), T5 (95\% wheat flour, $5 \%$ peel powder)

Mean score of texture for different treatments were T0 (7.23), T1 (6.99), T2 (7.05), T3 (7.14), T4 (6.77) and T5 (6.54). Maximum increase showed in T0 (7.23) followed by T3 (7.14) while minimum increase occurred in T5 (6.54). It was observed that citrus peel in the cake did not showed significant difference $(p<0.05)$. But the addition of $3 \%$ is much closer to the control and showed that the cake improved in its texture quality as its mean is statistically different from all other treatments. So this result proved that the addition of citrus peel up to $3 \%$ improved the texture of cake and acceptable in the texture characteristics. The score in the range 7 to 7.9 means that the judges like the sample having $3 \%$ citrus peels at moderate level on hedonic scale. The results were closely related to the work of [21, 22].

Analysis of variance showed that treatments had a remarkable effect on overall acceptability of citrus peel cake. Mean score for treatment were T0 (7.19), T1 (6.95), T2 (6.98), T3 (7.05), T4 (6.64) and T5 (6.34). Maximum mean value was showed in T0 (7.19) followed by T3 (7.05) while minimum mean value occur in T5 (6.34). Among the different level of citrus peel it was noticed 
that the judges gave the maximum score to the sample T3 that is (7.05) this means that it is slightly liked by the judges of the panelists. So it is concluded that the addition of citrus peel in the cake was found to be acceptable on the basis of overall acceptability up to $3 \%$ citrus peel addition. These results were closely related to the findings of $[19,21]$.

\section{Conclusion}

From the current results it is concluded that blending of wheat flour up to $3 \%$ citrus peel flour is suitable for cake development with acceptable sensory attributes. It is assumed from the study that blending of fine flour with citrus peel powder could develop appreciable quality cake containing high nutritious value. Addition of citrus peel, the chemical nature of citrus peel cake, Crude fat, crude fiber and ash contents increased whereas moisture and crude protein content reduced. Organoleptic attributes of citrus peel cake like color, taste, texture and overall acceptability were varied remarkably but within acceptable range. Further research work should be done to determine the influence of packaging and nutritional quality of citrus peel cake. There should be further work needed on preparation of nutritious baked products blended with citrus peel with other cereals. It is recommended that addition up to $3 \%$ citrus peel flour is acceptable in the cake.

\section{Authors' contributions}

Conceived and designed the experiments: $\mathrm{M}$ Iftikhar \& S Wahab, Performed the experiments: M Iftikhar, Analyzed the data: NU Taran \& NU Haq, Contributed materials/ analysis/ tools: SN Malik \& S Amber, Wrote the paper: SU Rehman.

\section{References}

1. Braddock RJ (1995). By-products of citrus fruits. Food Technol 49: 74-77. Cauvain SP \& Young L (2006). Baked products: Science, technology and practice. Oxford, UK; Blackwell Publishing.
2. Lee CC, Wang HF \& Lin SD (2008). Effect of isomaltooligosaccharide syrup on quality characteristics of sponge cake. Cereal Chem 85: 515-521.

3. Larmond E (1977). Laboratory Method of sensory evaluation of foods. Res Branch Canada Deptt of Agri Pub 1637.

4. Psimouli V \& Oreopoulou V (2012). The effect of alternative sweeteners on batter rheology and cake properties. J Sci Food \& Agri 92(1): 99-105.

5. Gomez M, Oliete B, Rosell CM, Pando V \& Fernández E (2008). Studies on cake quality made of wheat-chickpea flour blends. LWT-Food Sci Technol 41(9): 1701-1709.

6. Anuonye JC, Jigam AA \& Ndaceko GM (2012). Effects of Extrusion-Cooking on the Nutrient and Anti-Nutrient Composition of Pigeon Pea and Unripe Plantain Blends. J Appl Pharm Sci 02(05): 158-162.

7. FAO (2014).Citrus Fruit Statistics. Food and Agriculture Organization of United Nation; Rome (Italy).

8. Goudeau D, Uratsu SL, Inoue K, GoesdaSilva F, Leslie A, Cook D \& Dandekar AM (2008). Tuning the orchestra: Selective gene regulation and orange fruit quality. Plant sci 174(3): 310-320.

9. Magda RA, Awad AM \& Salim KA (2008). Evaluation of mandarin and Navel Orange Peels as Natural Sources of Antioxidant in Biscuits. Special volume of conference, pp 75-82.

10. Mueen-ud-din G, Salim-ur-Rehman FM, Anjum \& Nawaz H (2007). Quality of flat Bread (naan) from Pakistani wheat varities. Pak J Agri Sci 44(1).

11. Dogan IS \& Yildiz O (2010). Multiple response optimisations for the development of reduced-fat cake. Food Manufact Effic 3: 35-40.

12. AOAC (2005). Official Method of Analysis. 18th Ed., Association of 
Official analytical Chemist. Arlington; VA (USA).

13. Steel RGD \& Torrie JH (1997). Principals and Procedures of statistics. McGraw Hill Book Co. New York; Vide.

14. Azam S, Khan Z, Ahmad B, Khan I \& Ali J (2014). Production of single cell protein from orange peels using Aspergillus niger and Saccharomyces cerevisiae. Global $J \quad$ Biotech Biochem 9(1): 14-18.

15. Okpala LC \& Apku MN (2014). Effect of Orange Peel Flour on the quality characteristics of Bread. British J Appl Sci Technol 4(5): 823-830.

16. Bacha U, Nasir M, Khalique A, Anjum AA \& Jabbar MA (2011). Comparative assessment of various agro-industrial wastes for Saccharomyces cerevisiae biomass production and its quality evaluation as single cell protein. $J$ Anim Plant Sci 21(4): 844-849.

17. Butt MS, Ihsanullah QM, Anjum FM, Aziz A \& Atif RM (2004). Development of minerals-enriched brown flour by utilizing wheat milling byproducts. Nutr \& Food Sci 34(4): 161165.

18. Nassar AG, Abdel-Hamied AA \& ElNaggar EA (2008).Effect of Citrus by products Incorporation on Chemical, Rheological and organoleptic Characteristics of Biscuits. World $J$ of Agri Sci 4(5): 612-616.

19. Reis SF, Rai DK \& Abu-Ghannam N (2012). Apple pomace as potential ingredient for the development of new functional foods. International Conference on Food Safety, Quality and Nutrition (ICFSQN), Manchester, UK, 61-66.

20. Sanchez MC, Plaza L, Elez MP, DeAncos B, Martin BO \& Cano MP (2005). Impact of high pressure and pulsed electric fields on bioactive compounds and antioxidant activity of orange juice in comparison with traditional thermal processing. J Agri Food Chem 53(11): 4403-4409.

21. Lin SD, Hwang CF \& Yeh CH (2003). Physical and sensory characteristics of chiffon cake prepared with erythritol as replacement for sucrose. $J$ Food Sci 68(6): 2107-2110.

22. Ghasemi KY, Ghasemi \& Ebrahimzadeh MA (2009). Antioxidant activity, phenol and flavonoid contents of 13 citrus species peels and tissues. Pak J Pharm Sci 22(3): 277-281. 